\title{
Lead Education and Discovery: Engaging young student scientists in a community health project
}

\author{
SANDRA WALSER ${ }^{1}$, NICOLAS PERDRIAL ${ }^{1}$, CHRISTINE $^{2}$ \\ MASSEY $^{1}$, DAVID MCNALLY ${ }^{2}$ AND PAUL BIERMAN ${ }^{1}$ \\ ${ }^{1}$ University of Vermont \\ ${ }^{2}$ Winooski High School \\ Presenting Author: sandra.walser@comcast.net
}

The negative health effects of low-level lead $(\mathrm{Pb})$ exposure have been gaining significant attention - often within the lens of environmental justice. Although $\mathrm{Pb}$ neurotoxic effects are particularly harmful for the neurological development of children, the danger is often unknown to the most vulnerable communities. Preliminary assessments of soils within Burlington and Winooski, Vermont, USA, have found a prevalence of elevated $\mathrm{Pb}$ in residential soils, due to legacy paint. Because of its source, $\mathrm{Pb}$ contamination is an issue of environmental equity. Contamination disproportionately affects low-income households and people of color, an issue exacerbated by the large rental population in the cities of Burlington and Winooski.

Through a US Environmental Protection Agency (EPA)supported project, the University of Vermont has partnered with 7th-12th grade teachers from local Burlington and Winooski schools to recruit over 1,000 students as community scientists. We designed and implemented a project protocol based on online content (educational videos) and hands-on learning (soil and water sampling) to increase student awareness about $\mathrm{Pb}$ contamination in soil and water. We have used GIS tools to highlight local environmental justice issues. To date, we have worked with more than 200 students in 9 classes. Several properties with elevated $\mathrm{Pb}$ have been identified, and resources have been provided for further assessment by the Burlington Lead Program, a local abatement initiative. Ultimately, this project aims to serve as a replicable community science template for other cities where $\mathrm{Pb}$ contamination may be an issue of environmental health.

While greater vigilance and action at the institutional level will be necessary for substantial movement towards eliminating national childhood $\mathrm{Pb}$ exposure, this community science project serves to achieve several important goals, including: 1) Education of vulnerable populations and 2) Promoting collaborative, community research in science. By engaging students in an environmental justice project affecting them directly, we aim to encourage a generation of community and environmental problem solvers from varying socioeconomic and cultural backgrounds. 